\title{
Explorando a gamificação na formação docente com o software Geogebra
}

\author{
Rafaela Padilha*, Carine G. Webber**
}

\section{Resumo}

A gamificação é uma estratégia por meio da qual elementos de jogos são aplicados em um contexto que não é naturalmente um jogo. Para que a gamificação se torne um recurso pedagógico, os professores necessitam de conhecimentos prévios. Em vista disso, este artigo trata da realização de uma capacitação para professores de matemática sobre gamificação usando o software Geogebra. Por um semestre, 22 professores participaram da capacitação e produziram objetos de aprendizagem gamificados. Os resultados desta atividade revelam que a formação continuada é um dos meios possíveis para se compartilhar estratégias gamificadas que repercutam com sucesso nas práticas docentes.

Palavras-chave: Ensino de Matemática, Gamificação, Formação docente, Geogebra.

\section{Introdução}

A sociedade apresenta-se em pleno processo de desenvolvimento tecnológico, acelerado pelo evento da pandemia. De acordo com Lima e Silva Neto (2012), as mudanças sociais ocorrem com grande velocidade e quase sempre influenciam o contexto educacional. Consequentemente, elas acabam interferindo na atuação do professor, que precisa remodelar sua prática para atender as demandas da sociedade. Evidencia-se, assim, a importância de um processo constante de formação continuada de professores, que necessitam buscar atualização e aprimoramento da sua prática pedagógica.

\footnotetext{
Mestre em Ensino de Ciências e Matemática, Universidade de Caxias do Sul, RS, Brasil. E-mail: rpadilha3@ ucs.br

* Doutora em Ciência da Computação pela Université Joseph Fourier, Grenoble, França. Professora do Programa de Pós-graduação em Ensino de Ciências e Matemática, Universidade de Caxias do Sul, RS, Brasil. E-mail: cgwebber@ucs.br
} 
Se, por um lado, os avanços da vida moderna podem ser incorporados à prática docente, por outro mais profundo, surgem questionamentos de ordem didática. Isso porque não basta importar modelos ou recursos externos à sala de aula, é preciso repensar as estratégias de ensino por meio de tais recursos (ALMOULOUD, 2005). Nesse sentido, os professores precisam desenvolver competências profissionais que lhes permitam selecionar, adaptar e fazer uso de recursos em sala de aula (Ribeiro e Ponto, 2000). A formação continuada é o mecanismo pelo qual o professor pode se preparar para novas situações em sala de aula. A construção do conhecimento pelos estudantes vai depender de como o professor, como mediador, aborda os saberes a ensinar, buscando motivar o estudante no desenvolvimento de habilidades e conhecimentos.

Trabalhos recentes apontam para o uso de estratégias gamificadas nos processos de ensino e aprendizagem. Busarello et. al (2014) afirmam que há evidências de que a sociedade atual está cada vez mais interessada por jogos, pois além de proporcionar prazer, as dinâmicas dos jogos funcionam como um impulso motivacional para o indivíduo. Nessa lógica, Furió e outros (2013) complementam essa afirmação apontando que o ato de jogar é um meio para que o sujeito desenvolva habilidades cognitivas, treinando a memória e a atenção. Tais habilidades são fundamentais especialmente na área da matemática, necessitando ser exercitadas e aprimoradas. Por estas razões, o ensino de matemática tem sido alvo de intensa pesquisa e estudo, visando desenvolver experiências de aprendizado aos estudantes que os motivem e interessem, conciliando-as com atividades lúdicas. Nesta problemática, propõe-se neste artigo, recorte de uma dissertação de mestrado, reflexões e análises sobre maneiras de conciliar modelos da gamificação com o ensino de matemática, fazendo uso de softwares educacionais.

Graças ao aprimoramento das tecnologias, diversos softwares educacionais vêm sendo desenvolvidos na área da matemática. Um importante software educacional desta área é o software Geogebra1. A partir de sua utilização é possível construir e manipular formas geométricas, representações de funções, e diversas construções matemáticas (BASTOS, POFFAL e SCHNEIDER, 2015). O software permite trabalhar com a geometria de maneira dinâmica, proporcionando aos estudantes uma melhor visualização e a possibilidade de explorar as construções realizadas, o que colabora para aumentar a compreensão de conteúdos matemáticos (SILVA e PENTEADO, 2013). Além das operações sobre elementos geométricos, o software Geogebra possui recursos para a construções de objetos de aprendizagem, incluindo 
funcionalidades para programações simples. Essa perspectiva favorece a implementação de elementos de jogos, propostos pela gamificação, no próprio Geogebra, motivando a sua utilização no contexto deste trabalho.

Diante do exposto, esse artigo trata da temática da formação continuada de professores que atuam na área da matemática a fim de que eles desenvolvam estratégias de ensino a partir da utilização da gamificação aliada ao software GeoGebra. Para isso, desenvolveu-se e avaliou-se uma capacitação para professores da educação básica, cuja fundamentação (seção 2) e detalhamento (seção 3) são apresentados neste artigo. Como considerações finais (seção 5), o artigo aborda as potencialidades da formação proposta e avalia seus resultados (ilustrados na seção 4).

\section{Formação docente continuada em tecnologias}

A inserção do computador nos processos de ensino e aprendizagem trouxe novas possibilidades e consequente melhoria de tais processos. Papert, um dos primeiros defensores do uso das tecnologias na Educação, definiu como sendo o principal objetivo da informática na educação proporcionar a aprendizagem a partir da criatividade e liberdade de construção pelos estudantes, possibilitando a utilização de conceitos matemáticos, criação de modelos e fórmulas conforme sua necessidade e interesse. Defendendo a utilização do computador nos processos de ensino e aprendizagem, onde seja preciso proporcionar um ambiente em que o sujeito possa construir seu conhecimento, Papert desenvolveu a teoria Construcionista (PAPERT, 2008). Ele afirma em sua obra que a atitude construcionista busca ensinar de maneira a produzir uma maior aprendizagem a partir do mínimo de ensino. Isso não significa que a solução seja reduzir a quantidade de ensino, mas sim promover uma mudança na maneira de ensinar. Para exemplificar, Papert faz uma comparação ao seguinte provérbio africano: "se um homem tem fome, você pode dar-lhe um peixe, mas é melhor dar-lhe uma vara e ensiná-lo a pescar" (PAPERT, 2008, p. 134).

A visão construcionista se construiu sobre a percepção de que as crianças farão melhor descobrindo (pescando) por si mesmas o conhecimento específico de que precisam. A educação organizada ou informal pode ajudar a certificar-se de que elas estarão sendo apoiadas moral, psicológica, material e intelectualmente em seus esforços. Mas de fato, o tipo de conhecimento que as crianças mais precisam é o que as ajudará a obter mais conhecimento (PAPERT, 2008, p.135). 
Apoiado sobre a possibilidade das construções que o computador permitiria, $\mathrm{Pa}-$ pert previu os benefícios que poderiam advir do seu uso em sala de aula. Preocupado com a construção do conhecimento, ele vislumbrou igualmente que a tecnologia provocaria um olhar de particular interesse por parte dos estudantes. Esse fator é peça fundamental no construcionismo pois, segundo ele, a construção do conhecimento só acontece quando o sujeito constrói um objeto de seu interesse, seja um desenho, uma imagem, um texto, um mapa ou um programa de computador.

Na perspectiva de Papert, o conhecimento emerge de interações e construções, para se materializar em artefatos concebidos e produzidos pelos estudantes. Tal mudança contextual repercute no ensino e demanda professores aptos a elaborarem práticas pedagógicas apropriadas, que privilegiem a iniciativa e possibilitem a exploração do meio computacional. Para isso, assim como vê-se em outras profissões, o professor também se encontra em constante busca por aperfeiçoamento.

Em uma perspectiva realista e prática, o desenvolvimento profissional do professor é um processo que acontece no decorrer da própria atuação docente, possibilitando um novo sentido à prática pedagógica, novas contextualizações e ressignificação da sua atuação. Se torna necessário e importante, ao falar de formação docente, considerar os avanços tecnológicos. De fato, um assunto que se destaca nos dias atuais é a formação docente tecnológica, pois para que as tecnologias possam ser inseridas nos processos de ensino e aprendizagem o professor precisa estar preparado para conduzir esse trabalho.

Constitui um dos papeis do professor explorar estratégias de ensino e aprendizagem para estimular os estudantes no desenvolvimento de suas habilidades (JUNCKES, 2013). Nesse processo, o professor precisa definir a estratégia de ensino mais adequada e escolher qual é o recurso educacional mais apropriado para promover a aprendizagem. Por este motivo, a formação continuada de professores é um dos principais elementos para o sucesso das aprendizagens visadas pois, para poder fazer as melhores escolhas sobre como ensinar, é importante que constantemente eles estejam buscando formação atualizada (VALENTE, 2008).

Segundo Almeida (2001), para incorporar os recursos tecnológicos nas aulas os professores necessitam adquirir competências quanto ao uso de tais recursos, estabelecendo uma ligação entre as habilidades incorporadas e a sua prática pedagógica. À medida que avançam neste processo de aprendizado contínuo, os professores se vêem menos como meros usuários das tecnologias, para se tornarem produtores de material didático a partir das tecnologias. Tal visão está alinhada com os princípios defendidos 
por Papert, de que o uso das tecnologias não deve ser feito visando o ensino tecnológico em si, mas buscando o desenvolvimento de habilidades ligadas ao pensamento computacional. O pensamento computacional compreende um conjunto de habilidades desejadas aos profissionais de todas as áreas, para que possam fazer uso da tecnologia na produção de novos conhecimentos. Na formação docente, esta se insere no conjunto de habilidades que contribuem para a inserção de inovações nas práticas pedagógicas. No contexto deste trabalho, toma-se a gamificação como recurso pedagógico e computacional que os professores podem se valer nas suas práticas pedagógicas.

\section{A gamificação no processo de ensino}

A partir do interesse crescente em atividades lúdicas, designers de games vêm se dedicando nos últimos anos na aplicação de princípios de jogos em diferentes áreas de atuação, tais como: na saúde, administração, esportes, aumento de produtividade e educação (VIANNA et.al., 2013). Nessa perspectiva, Nick Pelling, programador de computadores e pesquisador britânico, idealizou o termo "gamificação" em 2003.

O termo gamificação trata da utilização de mecanismos de jogos voltados ao objetivo de resolver problemas e despertar um engajamento entre um público específico (VIANNA et al., 2013). De acordo com Alves e outros autores (2014, p. 76), a gamificação constitui uma forma de utilização da mecânica dos games em cenários non games. Desta forma, cria-se espaços de aprendizagem mediados pelo desafio, pelo prazer e entretenimento. Complementarmente, Kapp (2012, p. 32) define a gamificação como "a utilização de mecânica, estética e pensamento baseados em games para engajar pessoas, motivar a ação, promover a aprendizagem e resolver problemas”.

De acordo com McGonigal (2012), os games apresentam quatro características que os definem, sendo elas a meta, as regras, o sistema de feedback e a participação voluntária. Para autores como Vianna e outros (2013), aspectos como a interatividade, suporte gráfico, narrativa, recompensas, competitividade e virtualidade são igualmente características comuns de jogos.

Entende-se que abordar esses conceitos em atividades educacionais é uma importante estratégia quando o objetivo é promover a aprendizagem. Segundo Busarello et al. (2013, p. 12), “o foco da gamificação é envolver emocionalmente o indivíduo utilizando mecanismos provenientes de jogos, favorecendo a criação de um ambiente propício ao engajamento do indivíduo". Além disso, Gee (2003, apud ALVES, 2014) 
afirma que a gamificação é um instrumento com potencial efetivo para promover a educação, pois incentiva uma aprendizagem ativa e crítica.

Nesse sentido, uma alternativa para inserir a gamificação nos processos de ensino e aprendizagem pode ser por meio da utilização de Objetos de Aprendizagem Gamificados (OAGs). Esses objetos são estruturados em jogos ou abordam alguns de seus elementos. Para que os objetos de aprendizagem se tornem gamificados é preciso adaptar seu design, adotando algumas características específicas de jogos de acordo com os objetivos que se pretende atingir com a atividade prevista (ALVES e TEIXEIRA, 2014).

Buscando-se aproximar a gamificação de atividades matemáticas, foco deste trabalho, foi preciso pensar em como desenvolver os OAGs. Para isso partiu-se de softwares como o Geogebra, amplamente utilizado no ensino de matemática. Por meio dos estudos realizados identificou-se a viabilidade no uso do Geogebra neste projeto, motivado pelo fato dele oferecer recursos simples de programação e construção de objetos interativos de aprendizagem, até então pouco explorados em trabalhos relacionados.

A partir da utilização do software Geogebra é possível construir e manipular formas geométricas, representações de funções e diversas construções matemáticas. O software permite trabalhar com a geometria de maneira dinâmica, proporcionando aos estudantes uma melhor visualização e a possibilidade de explorar as construções realizadas, o que colabora para aumentar a compreensão de conteúdos matemáticos. Estas funcionalidades são bem conhecidas pelos docentes de matemática pois o Geogebra é um micromundo da Geometria, amplamente utilizado em sala de aula. Contudo, existem funcionalidades nele que extrapolam a Geometria, permitindo ao seu usuário pequenas programações para construção de simulações, problemas e interações. Tais construções são denominadas objetos de aprendizagem do Geogebra. Para o contexto deste artigo, buscou-se estender o uso do software Geogebra visando a construção de objetos de aprendizagem com elementos de games, a que denominamos objetos de aprendizagem gamificados (OAGs) do Geogebra. Sobre este tema tratou a capacitação docente proposta, descrita na seção seguinte.

\section{Percurso Metodológico}

O presente estudo compreendeu o desenvolvimento de práticas inseridas em uma formação docente (curso de Pós-Graduação Lato Sensu - Especialização em Ensino de Matemática para a Educação Básica no decorrer da disciplina Tecnologias 
Educacionais). Participaram do estudo 22 professores que lecionam Matemática na educação básica, desde os anos iniciais do ensino fundamental até o ensino médio. Para a realização da atividade utilizou-se um laboratório de informática com um computador por participante com instalação prévia do software Geogebra. Além disso, outros materiais como Questionário de Sondagem Inicial, Síntese com os Elementos de Jogos, Roteiro para a Construção de um OAG, e Questionário de Avaliação sobre o OAG construído, fizeram parte dos elementos disponibilizados aos professores para a realização da pesquisa.

O quadro 1 apresenta as oito etapas do percurso metodológico desenvolvido. Cada etapa foi realizada em um ou mais encontros com os professores. Todas as etapas foram acompanhadas e documentadas. Os resultados e conclusões relatados neste artigo foram obtidos por meio de aquisição com autorização dos dados textuais e produções do professores em formação.

\section{Quadro 1: Etapas do percurso metodológico}

\begin{tabular}{|c|c|}
\hline Etapa & Descrição \\
\hline $\begin{array}{l}\text { 1. Entrevista de sondagem } \\
\text { inicial }\end{array}$ & $\begin{array}{l}\text { Aplicação de um questionário pela professora ministrante com o objetivo de } \\
\text { identificar as concepções prévias dos professores participantes sobre a utili- } \\
\text { zação de tecnologias educacionais e sobre a gamificação em um período de } \\
45 \text { minutos. }\end{array}$ \\
\hline $\begin{array}{l}\text { 2. Planejamento da capaci- } \\
\text { tação sobre a construção de } \\
\text { OAG no software GeoGebra }\end{array}$ & $\begin{array}{l}\text { Planejamento pela professora ministrante de uma capacitação sobre a cons- } \\
\text { trução de OAGs no software GeoGebra a partir dos resultados obtidos a partir } \\
\text { do questionário de sondagem inicial. }\end{array}$ \\
\hline $\begin{array}{l}\text { 3. Apresentação e orientação } \\
\text { sobre o software GeoGebra }\end{array}$ & $\begin{array}{l}\text { A professora ministrante conduziu uma aula expositiva sobre a utilização das } \\
\text { ferramentas e funcionalidade do software GeoGebra no laboratório de informá- } \\
\text { tica por dois períodos de } 45 \text { minutos cada. }\end{array}$ \\
\hline $\begin{array}{l}\text { 4. Apresentação e conceitua- } \\
\text { ção sobre a gamificação }\end{array}$ & $\begin{array}{l}\text { A professora ministrante conduziu uma aula expositiva sobre os principais } \\
\text { conceitos da gamificação no laboratório de informática por um período de } 45 \\
\text { minutos. }\end{array}$ \\
\hline $\begin{array}{l}\text { 5. Análise e construção de } \\
\text { OAGs }\end{array}$ & $\begin{array}{l}\text { A professora ministrante conduziu a análise de maneira expositiva e dialoga- } \\
\text { da sobre as características, funcionalidades e conceitos da gamificação dos } \\
\text { OAGs no laboratório de informática por dois períodos de } 45 \text { minutos cada. }\end{array}$ \\
\hline $\begin{array}{l}\text { 6. Proposta de um projeto } \\
\text { gamificado no GeoGebra }\end{array}$ & $\begin{array}{l}\text { Em duplas, os professores participantes construíram um OAG no software Ge- } \\
\text { oGebra. A construção iniciou na aula por dois períodos de } 45 \text { minutos cada, e } \\
\text { foi concluída no intervalo de uma semana. }\end{array}$ \\
\hline $\begin{array}{l}\text { 7. Apresentação e discussão } \\
\text { sobre o projeto gamificado } \\
\text { no GeoGebra }\end{array}$ & $\begin{array}{l}\text { Os professores participantes apresentaram de maneira oral e expositiva os } \\
\text { OAGs construídos por três períodos de } 45 \text { minutos cada. }\end{array}$ \\
\hline $\begin{array}{l}\text { 8. Entrevista de avaliação } \\
\text { sobre o projeto gamificado } \\
\text { no GeoGebra }\end{array}$ & $\begin{array}{l}\text { A professora ministrante aplicou um questionário com o objetivo de avaliar o } \\
\text { projeto de gamificação em um período de } 45 \text { minutos. }\end{array}$ \\
\hline
\end{tabular}

Fonte: os autores 


\section{Resultados e Discussão}

A capacitação foi oferecida e concluída no período de um semestre. As etapas indicadas no quadro 1 foram realizadas e registradas para análise posterior. A primeira etapa permitiu a realização de uma sondagem inicial. A partir das respostas obtidas nesta sondagem identificou-se que a maioria dos professores respondentes atuava há menos de cinco anos na docência, possuindo conhecimentos em nível intermediário de informática. Os softwares relatados como os mais utilizados foram MS-Word, MS-Excel, MS-PowerPoint e outros de uso matemático. Alguns dos professores relataram conhecer o software Geogebra. Com relação ao uso de jogos educacionais, a maioria dos professores soube conceituar jogos, mas não compreendia o conceito de gamificação. Em relação à utilização de jogos e tecnologias educacionais em sala de aula, constatou-se que $25 \%$ deles (5 professores) nunca haviam usado em aula. Mesmo assim, todos os professores afirmaram que a informática pode aprimorar os processos de ensino e aprendizagem. A maioria dos professores afirmou que em suas aulas os estudantes demonstravam interesse pelo uso das tecnologias e dos jogos. Todos os respondentes afirmaram ainda a percepção de que os estudantes demonstram maior interesse e rendimento nas aulas quando há disponibilidade dos recursos tecnológicos.

No segundo, terceiro e quarto encontros foram trabalhados os conceitos de jogos, gamificação além de uma abordagem aprofundada sobre o software Geogebra, os seus mecanismos para programação e construção de objetos de aprendizagem integrada à gamificação. No quinto e sexto encontros partiu-se para a concepção e construção dos objetos gamificados pelos professores.

Em relação aos OAGs construídos pelos professores ${ }^{2}$, todos eles foram primeiramente analisados, quanto às suas características gerais (nome, assunto, ano escolar do OAG, formas de interagir, conceitos da gamificação e ferramentas computacionais utilizadas). A partir da primeira análise dos OAGs foi possível perceber que os professores selecionaram conteúdos temáticos para os objetivos assumindo que eles seriam necessários em situações nas quais os estudantes apresentavam dificuldades de aprendizagem. Observou-se que o tema da matemática de maior incidência foram as Funções do $1^{\circ}$ grau, conteúdo associado ao $9^{\circ}$ ano do Ensino Fundamental. Também se repetiram assuntos relacionados aos $5^{\circ}$ e $6^{\circ}$ anos. Apenas um dos OAGs foi desenvolvido para estudantes do $1^{\circ}$ ano do Ensino Médio. 
A fim de ilustrar as produções, apresenta-se o OAG Frações e Pizza (figura 1a e 1b). Ele aborda o tema de representação de frações tratando uma fração como sendo composta por um numerador e um denominador. Ele oferece uma visualização da divisão de uma pizza em fatias iguais. Para realizar esta atividade, o estudante deve observar em quantas fatias a pizza está dividida (denominador) e quantas fatias estão destacadas (numerador). A partir desta observação, a fração (numerador/ denominador) correspondente deve ser escrita pelo estudante.

A fração, resposta do estudante, pode ser verificada selecionando-se a caixa Resposta, conforme ilustrado na Figura 1b. Além de corrigir, o objeto gera repetidamente novas configurações de pizzas e corrige as respostas. Embora seja um objeto simples, ele é interativo e produz novos problemas ao estudante, engajando-o em um desafio e pontuando seus acertos. Os professores que desenvolveram este OAG buscaram um problema simples (identificação da fração), no qual pudessem explorar os recursos de programação aprendidos (geração de problemas aleatórios, repetição de problemas, correção de problemas, exibição de mensagens aos estudantes, entre outras funcionalidades utilizadas). O OAG foi avaliado como um artefato que torna o problema claro e compreensível aos estudantes, conciliando o tema escolhido com os recursos disponíveis pelo software, como programação, interface clara e interatividade.

Figura 1a: OAG Frações e Pizza - tela inicial

FRAÇÕES

Identifique e escreva no local indicado qual é a fração correspondente ao número de fatias preenchidas sobre o número total de fatias da pizza.

Em seguida, verifique se sua resposta está correta. Para tentar novamente clique no botảo "Sortear".

Qual é a fração correspondente?
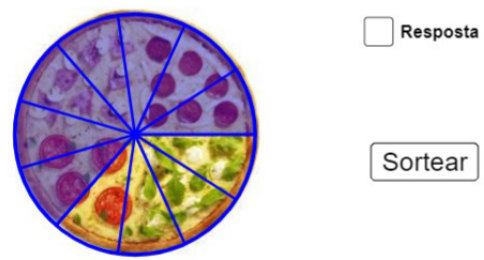

Figura 1b: OAG Frações e Pizza - tela final

\section{FRAÇŌES}

Identifique e escreva no local indicado qual é a fração correspondente ao número de fatias preenchidas sobre o número total de fatias da pizza. Em seguida, verifique se sua resposta está correta. Para tentar novamente clique no botão "Sortear".

\section{Qual é a fração correspondente? $7 / 11$}

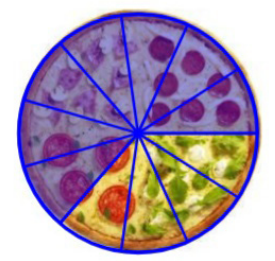


Um segundo OAG a ser apresentado denomina-se Acerte o Alvo (figura 2a e 2b). Ele aborda o tema das coordenadas cartesianas com o objetivo de demonstrar o significado de um ponto (x,y) e como localizá-lo no plano cartesiano. Essa atividade é direcionada aos estudantes do $9^{\circ}$ ano do ensino fundamental. Para realizar a atividade o estudante deve indicar quais são as coordenadas cartesianas (x,y) em que o alvo se encontra e informá-las no campo "Coordenadas do Alvo".

Figura 2a: OAG Acerte o Alvo - tela inicial

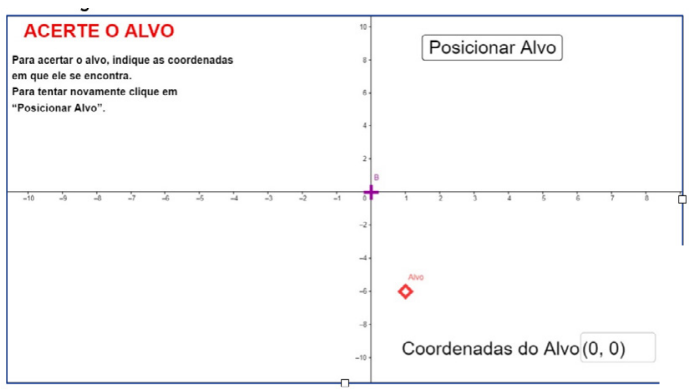

Figura 2b: OAG Acerte o Alvo - tela final

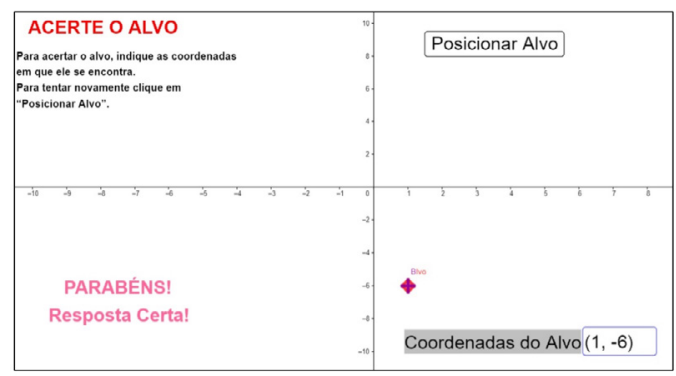

O segundo OAG foi avaliado como um artefato de representação clara aos estudantes, tratando um tema simples mas que gera dúvidas. Foram empregados elementos de jogos, apoiados na programação e na interatividade possibilitada pelo Geogebra.

Nas duas etapas finais da capacitação houveram as apresentações dos objetos desenvolvidos e a aplicação de um instrumento final de avaliação. Todos os participantes apresentaram e compartilharam seus objetos gamificados. $\mathrm{O}$ instrumento final de avaliação permitiu atestar a apreciação dos professores quanto a capacitação realizada. De maneira unânime, os professores aprovaram a capacitação, e reforçaram que por meio dela puderam conhecer os conceitos da gamificação, como planejar e criar um OAG. O desafio da construção de um OAG foi considerado, pelos professores, como uma superação. Como trabalhos futuros, dois professores vislumbraram a possibilidade de propor aos seus estudantes a construção de objetos gamificados, a fim de incentivar a inserção de elementos de jogos, algo tão corriqueiro para um estudante, somada a criação de objetos gamificados, nas aulas de matemática. 


\section{Conclusões}

O presente artigo apresentou uma proposta de capacitação docente, visando a formação continuada sobre o uso de estratégias de ensino baseadas em recursos tecnológicos. A inserção de uma ferramenta de software no ensino pode ser explorada sob dois eixos: ensino do uso do software e construção de novos artefatos a partir do uso do software. Neste trabalho explorou-se o segundo eixo, que se alinha com as propostas do construcionismo de Papert (2008), segundo o qual não deve-se primar pela instrumentalização mas pela inserção da tecnologia na construção de objetos de conhecimento, tanto pelo professor quanto pelos alunos.

A capacitação realizada contou com a colaboração de 22 professores que produziram OAGs aplicados ao ensino de matemática com o Geogebra. Os objetos construídos envolveram temas além da Geometria, graças aos recursos de programação e interação do Geogebra. Embora os recursos do Geogebra sejam simples, eles possibilitaram pequenas programações e entradas de dados. Para as programações os professores aprenderam a escrever expressões condicionais e lógicas, além de controle de laços de repetição e instruções de entrada e saída de dados. Todos esses componentes constituem automatizações e refletem comportamentos esperados de um objeto de aprendizagem realmente gamificado.

A construção dos OAGs foi considerada um desafio pelos professores, mas também uma atividade motivadora. Por meio dela, percebeu-se que os professores estavam dispostos a buscar estratégias inovadoras que, muitas vezes, são desconhecidas por eles. Mesmo nunca tendo trabalhado com o software Geogebra, a maioria dos professores demonstrou interesse em aprender e buscar soluções para as dificuldades encontradas no desenvolvimento dos objetos. Os professores avançaram muito na exploração dos recursos do software de acordo com o que pretendiam construir, como por exemplo, a programação, que permitiu incluir elementos de jogos nos objetos do Geogebra.

Por fim, e de acordo com os resultados obtidos a partir do questionário de sondagem final, os professores confirmaram interesse em prosseguir nas suas formações, incentivados pelas propostas de jogos permeados pelas tecnologias. Como trabalhos futuros prevê-se a oferta de novas turmas e avanços nas produções gamificadas, integrando-as a plataformas diversificadas. 


\section{Gamification in the context of teacher formation with Geogebra}

\section{Abstract}

Gamification is a strategy by which game elements are applied in a context that is not naturally a game. In the classroom, gamification, as a pedagogical resource, is integrated with various contents but demands particular teacher's prior knowledge. In view of this, this article deals with the conception and realization of a gamification course for math teachers, usingt he Geogebra software. During a semester, 22 teachers participated in a course and produced gamified learning objects. The results obtained through his work, presented in this article, show that continuing training is one of the possible means of sharing teaching strategies that have a positive impact on teaching practices.

Keywords: Math teaching, Gamification, Teacher formation, Geogebra.

\section{Notas}

1 Disponível em http://www.geogebra.org

2 Os OAG construídos pelos professores na capacitação estão publicados na página oficial do software GeoGebra, no link https://www.geogebra.org/u/padilharafaela\#materials/created

\section{Referências}

ALMEIDA, Maria Elizabeth Bianconcini. Educação, projetos, tecnologia e conhecimento. São Paulo: PROEM, p. 111-122, 2001.

ALMOULOUD, Saddo Ag. Informática e Educação Matemática. Revista de Informática Aplicada, v. 1, n. 1, 2005.

ALVES, Lynn Rosalina Gama; MINHO, Marcelle Rose da Silva; DINIZ, Marcelo Vera Cruz. Gamificação: diálogos com a educação. In: Fadel, Luciane Maria et al. (Org.). Gamificação na educação. São Paulo: Pimenta Cultural, 2014.

ALVES, Marcia Maria; TEIXEIRA, Oscar. Gamificação e objetos de aprendizagem: contribuições da gamificação para o design de objetos de aprendizagem. In: Fadel, Luciane M. et al. (Org.). Gamificação na educação. São Paulo: Pimenta Cultural, 2014.

BASTOS, Débora Oliveira; POFFAL, Cristiana Andrade; MENEGHETTI, Cinthya Schneider. Estudo da Circunferência no Ensino Médio: Sugestões de Atividades com a Utilização do Software GeoGebra. Ciência e Natura, v. 37, n. 3, 2015.

BUSANELLO, Raul Inácio; ULBRICHT, Vania Ribas; FADEL, Luciane Maria. A gamificação e a sistemática de jogo: conceitos sobre a gamificação como um recurso motivacional. In: Fadel, Luciane Maria et al. (Org.). Gamificação na educação. São Paulo: Pimenta Cultural, 2014. 
SILVA, Guilherme Henrique Gomes; PENTEADO, Miriam Godoy. Geometria dinâmica na sala de aula: o desenvolvimento do futuro professor de matemática diante da imprevisibilidade. Ciência \& Educação, Bauru, v. 19, n. 2, p. 279-292, 2013.

FURIÓ, David; GONZALEZ-GANCEDO, Santiago; JUAN, M-Carmen.; SEGUI, Ignacio; COSTA, María. The effects of the size and weight of a mobile device on an educational game. Journal Computers \& Education, Virginia, v. 64, p. 24-41, 2013.

GEE, James Paul. What video games have to teach us about learning and literacy. New York, Palgrave MacMillan, 2003.

JUNCKES, Rosani Casanova. A prática docente em sala de aula: mediação pedagógica. Simpósio sobre Formação de Professores. Educação Básica: Desafios frente às desigualdades Educacionais, 2013.

KAPP, Karl. The Gamification of Learning and Instruction: Game-based Methods and Strategies for Training and Education. San Francisco: Pfeiffer, 2012.

LIMA, Iranete Maria Silva; SILVA NETO, João Ferreira. O que pensam professores que ensinam matemática na educação básica sobre a formação continuada? Pesquiseduca, v. 4, n. 7, p. 06-23, 2012.

McGONIGAL, Jane. A realidade em jogo: por que os games nos tornam melhores e como eles podem mudar o mundo. Rio de Janeiro: Ed. Best Seller, 2012.

RIBEIRO, Maria José Bahia; PONTE, João Pedro da. A formação em novas tecnologias e as concepções e práticas dos professores de Matemática. Quadrante, p. 3-26, 2000.

PAPERT, Seymour A máquina das crianças: repensando a escola na era da informática. Porto Alegre: Artmed, 2008.

VALENTE, José Armando. Diferentes usos do computador na educação. Em Aberto, v. 12, n. $57,2008$.

VIANNA, Ysmar; VIANNA, Maurício; MEDINA, Bruno; TANAKA, Samara. Gamification, Inc.: como reinventar empresas a partir de jogos. Rio de Janeiro: 